\title{
Our Bariatric Surgery History: Where We Came From
}

\author{
Scott A. Shikora
}

Published online: 3 July 2014

(C) Springer Science+Business Media New York 2014

This coming August, we will gather in Montreal to participate (and celebrate) the XIX World Congress of IFSO. This is no small event. There will be thousands of participants, industry partners, and the media. The IFSO World Congress and the ASMBS Annual Meeting (now known as Obesity Week) have become significant medical conferences worthy of the respect of our non-bariatric colleagues.

Like many of the more senior bariatric surgeons and clinicians, I remember a different situation. I remember very small yearly meetings with only a handful of participants and little, if any, media attention. I recall a time when we did not proudly proclaim that we were bariatric surgeons, as many nonbariatric surgeons did not respect our discipline or our work. We were considered a fringe specialty based on little science and much experimentation. We had no voice in large surgical societies such as the American College of Surgeons. We also faced discrimination from the stable of surgical journals, which rarely published our work.

So what has changed?

What has changed is that our leaders had the courage to prevail. They continued to do the research and to publish the results. Fortunately, we had our own journals to publish our work. We demonstrated that our operative procedures were so much more than just weight reducing. We opened many eyes by showing that our procedures were truly metabolic. Lastly, we had the perseverance to continually refine our procedures, making them more efficacious, safe, and less invasive. We continued to think out of the box and create newer procedures based on our 60-year experience.

It has been said that, "Those who forget the past, are doomed to repeat it." This pertains to bariatric surgery, as well. We all need to know where we came from and how we got here. It is mandatory so that we do not repeat past mistakes and do not forget past advances.

Bariatric surgery has a rich history that we all should know. We need to also remember and celebrate the leaders who got us here. I have long thought that we needed to publish in Obesity Surgery a historical account of bariatric surgery. Who better than Henry Buchwald, MD, Ph.D., one of our true leaders and one of the many who is responsible for our success. He has participated as a surgeon and scientist since the early days. He also personally knew all who came before us. His insight and recollections are both historical and personal.

In this issue of Obesity Surgery is a thorough and thoughtful recount of the almost 60 years of bariatric surgery. I hope you find it as valuable as I have.

Cheers and I hope to see you in Montreal!

Scott

\footnotetext{
S. A. Shikora $(\bowtie)$

Brigham and Women's Hospital, 75 Francis Street, Boston,

MA 02115, USA

e-mail: SSHIKORA@PARTNERS.ORG
} 